This item was submitted to Loughborough's Research Repository by the author.

Items in Figshare are protected by copyright, with all rights reserved, unless otherwise indicated.

\title{
Atypically heterogeneous vertical first fixations to faces in a case series of people with developmental prosopagnosia
}

PLEASE CITE THE PUBLISHED VERSION

https://doi.org/10.1080/13506285.2020.1797968

PUBLISHER

Taylor \& Francis

VERSION

AM (Accepted Manuscript)

PUBLISHER STATEMENT

This is an Accepted Manuscript of an article published by Taylor \& Francis in Visual Cognition on 27 July 2020, available online: http://www.tandfonline.com/10.1080/13506285.2020.1797968.

\section{LICENCE}

CC BY-NC-ND 4.0

\section{REPOSITORY RECORD}

Wilcockson, Thom, Edwin Burns, Baiqiang Xia, Jeremy Tree, and Trevor Crawford. 2020. "Atypically Heterogeneous Vertical First Fixations to Faces in a Case Series of People with Developmental Prosopagnosia". Loughborough University. https://hdl.handle.net/2134/12646265.v1. 
Atypically heterogeneous vertical first fixations to faces in a case series of people with developmental prosopagnosia

3 Wilcockson, T.D.W..$^{1,2, *}$, Burns, E.J. ${ }^{3}$, Xia, B. ${ }^{4}$, Tree, J. ${ }^{5}, \&$ Crawford, T.J. ${ }^{2}$

4

$5 \quad{ }^{1}$ School of Sport, Exercise and Health Sciences, Loughborough University, Loughborough, LE1 1 6 3TU, UK

$7 \quad 2$ Psychology Department, Lancaster University, Lancaster, LA1 4TF, UK

$8 \quad{ }^{3}$ Department of Psychology, Edge Hill University, UK

$9 \quad{ }^{4}$ Faculty of Information Technology and Electrical Engineering, University of Oulu, Finland

$10 \quad{ }^{5}$ Psychology Department, Swansea University, Swansea, SA2 8PP, UK

$14 *$ Corresponding author email:

15 t.wilcockson@1boro.ac.uk 
RUNNING HEADER: PROSOPAGNOSIA FIRST FIXATIONS

17 Atypically heterogeneous vertical first fixations to faces in a case series of people with

18 developmental prosopagnosia

\section{ABSTRACT}

20 When people recognise faces, they normally move their eyes so that their first fixation is in the 21 optimal location for efficient perceptual processing. This location is found just below the centre22 point between the eyes. This type of attentional bias could be partly innate, but also an inevitable 23 developmental process that aids our ability to recognise faces. We investigated whether a group 24 of people with developmental prosopagnosia would also demonstrate neurotypical first fixation 25 locations when recognising faces during an eye tracking task. We found evidence that adults with 26 prosopagnosia had atypically heterogeneous first fixations in comparison to controls. However,

27 differences were limited to the vertical, but not horizontal, plane of the face. We interpret these 28 findings by suggesting that subtle changes to face-based eye movement patterns in developmental 29 prosopagnosia may underpin their face recognition impairments, and suggest future work is still 30 needed to address this possibility.

32 Keywords: Prosopagnosia; face recognition; eye tracking; first fixations; 
RUNNING HEADER: PROSOPAGNOSIA FIRST FIXATIONS

\section{INTRODUCTION}

People with developmental prosopagnosia (henceforth prosopagnosia) suffer lifelong impairments in face recognition in the absence of neurological damage (e.g. Behrmann \& Avidan, 2005; Galaburda \& Duchaine, 2003; Bate \& Tree, 2017; Towler \& Tree, 2018). While such cases are purported to have face-specific problems, they also suffer some non-face difficulties (Burns, Taylor \& Bukach, 2019), coupled with largely intact low-level visual and intellectual functions (Jones \& Tranel, 2001). Further, there is evidence of a genetic basis for the condition (see Grueter, et al., 2007), which could explain a strong familial link (e.g. Behrmann, \& Avidan, 2005; Bentin, et al., 1999; de Haan, 1999; Duchaine, 2000).

Why these individuals have difficulties with faces is at present unclear, however, there is growing evidence to suggest that these problems are due to deficits in holistic processing, that is, perceiving a face as a unitary whole (e.g. Van Belle, De Graef, Verfaillie, Busigny, \& Rossion, 2010). The disorder has been attributed to a failure to develop dedicated facial recognition mechanisms necessary for successful face recognition (Susilo \& Duchaine, 2013). In order to understand how prosopagnosia develops, researchers have traditionally viewed the faceprocessing system as a sequential and hierarchical multi-process system where impairments can occur at a variety of stages (Bruce and Young, 1986) with particular research focus on the latter stages (e.g., Bate \& Cook, 2012; Bate, Haslam, Jansari, \& Hodgson, 2009; Bennetts, Butcher, Lander, Udale, \& Bate, 2015; Duchaine et al., 2007; Lee, Duchaine, Wilson, \& Nakayama, 2010; Jackson, Counter \& Tree, 2017). However, it is also possible that the impairments occur at a much earlier stage of processing (e.g. Nemeth, et al., 2014) and may involve mechanisms that direct visual attention (specifically, eye movements) to faces. This, therefore, leads to an intriguing hypothesis: is failure to recognise faces a result of inappropriate allocation of attention towards faces? 
Successful face recognition may only require one or two fixations (Hsiao \& Cottrell,

2008), and is thought to be largely driven by attention toward the eye region (Gilad, Meng, \& Sinha, 2009; Sormaz, Andrews, \& Young, 2013). It is unclear whether this behaviour is merely a by-product of the social importance of looking someone in their eyes (e.g. Parkington \& Itier, 2018; Hills et al. 2013) or if it has a functional role in face recognition. In other words: is an attentional bias toward the eye region experience based or innate (see Gomez, Natu, Jeska, Barnett, \& Grill-Spector, 2018; Arcaro, Schade, Vincent, Ponce, \& Livingstone, 2017; Luo et al., 2017)? Previous research has indicated the importance of the eye region for early face recognition (e.g. Parkington \& Itier, 2018; Hills et al. 2013). Hills, Cooper and Pake, (2013) suggest that the attentional bias towards the eye region may maximise the perception and extraction of basic social cues. Attention to, and use of, eye information has indeed been shown to improve face identity, gender, and emotional expression judgements (Haig, 1985; Hills, Cooper, \& Pake, 2013; Schyns, Bonnar, \& Gosselin, 2002; Vinette, Gosselin, \& Schyns, 2004). Therefore the social importance of attending to the eyes seems clear.

However, the importance of attention for the eyes may not be entirely for social cognitive processes. Peterson and Eckstein (2012) looked at the optimal first fixation location for identifying faces. They observed that the human visual system optimises face identification performance by guiding eye movements towards a location just below the eyes, slightly left of the centre-point between the eyes. From this location the recogniser is able to see perceptually rich information in their fovea and peripheral vision. Therefore fixations toward the eye region seem to have a functional role for face recognition, as well as being important for social cognitive processes (e.g. Parkington \& Itier, 2018; Hills et al. 2013). The eye region may represent an area of the face where optimum face recognition can occur because it may enable the parallel processing of multiple salient facial features parafoveally i.e. the eyes, nose, mouth, and the distances between them are processed in parallel as an integrative whole. This would be important as subtle differences in the 


\section{RUNNING HEADER: PROSOPAGNOSIA FIRST FIXATIONS}

spatial relations between features (i.e., distances between eyes and mouth) are thought to be necessary for face recognition (Verfaillie, et al., 2014). Fixations to a central region of the face may therefore enable holistic processing, as multiple features could be processed within one fixation and processed as an integrative whole. However, the link between fixations and holistic processing is speculative. Galton's (1883) work over a century ago led to the hypothesis that "a face is perceived as an undecomposed whole, rather than as a collection of individual features" (Verfaillie, et al., 2014, p504), therefore, a first fixation to a central region may aid this process. Although note, the bias toward the eyes rather than directly in the centre of the face may be because the eye region contain the most rich information. Therefore, there appears to be an important distinction between the eyes and the eye region. The eyes are an important feature for social cognitive processes, whereas the eye region may be an optimum area for maximising the potential for holistic processing. However, separating the two may be difficult to measure and beyond the scope of the current paper. Indeed, the first fixation within this region may be a result of both processes. Overall, it would appear that the centre-point between the eyes is the most perceptually rich area for optimal face identification - at least, this is the case for those with intact face recognition. Would adults with prosopagnosia also therefore show the same bias for the optimal face identification location as those with neurotypical face recognition abilities?

Bobak, et al., (2017) found that adults with prosopagnosia spent less time than controls looking at the eye region. Further, acquired prosopagnosia cases also demonstrate a similar pattern of facial examination (e.g. Caldara et al., 2005; de Xivry, et al., 2008), whilst developmental cases may also have a preference for more external features during facial examination (see Schwarzer et al., 2007). In general, it would appear that adults with prosopagnosia make fewer fixations and demonstrate reduced regional sampling for famous (known) compared to novel faces (Bate, et al., 2008), spend more time examining the mouth and less time examining the eyes when compared to controls (e.g. Bate et al., 2015; cf. Lee, Corrow, Pancaroglu, \& Barton, 2019), potentially 


\section{RUNNING HEADER: PROSOPAGNOSIA FIRST FIXATIONS}

because adults with prosopagnosia are less well tuned to contrast information from the eye region (Fisher, Towler, \& Eimer, 2016), and may be impaired in holistic processing of the eye region but not the mouth region (DeGutis, et al., 2012).

Increased dwell time for the mouth region of the face is unlikely to enable holistic processing as this is not the optimal location for first fixations. For example, Peterson \& Eckstein (2012) found that forcing participants to maintain first fixation gaze points away from the optimal point of fixation degraded perceptual performance. This implies that failure to automatically orient toward this perceptually rich optimal area could lead to poorer performance. It may also suggest that adults with prosopagnosia may be impaired in directing the first fixation location, thus leading to degraded perceptual performance. Indeed, interventions designed to improve holistic processing lead to improved face recognition in people with prosopagnosia (DeGutis, Cohan, \& Nakayama, 2014). If an atypical first fixation for face stimuli plays a role in disrupting face recognition performance, we might expect to see atypical first fixation locations in prosopagnosia. This is the primary focus of the present work. Although, note, a recent study by Peterson et al. (2019) found that people with prosopagnosia and controls were analogous in first fixation patterns for a famous faces task, an unfamiliar face emotional judgment task, and a restricted fixation unfamiliar face identification. However, whether people with prosopagnosia are analogous to controls on an unrestricted unfamiliar face identification task with neutral expressions is still an open question.

A secondary focus of the current work is to examine whether first fixations are impaired when under different viewing conditions, which are designed to force either holistic or analytic processing.

Van Belle et al $(2010 ; 2014)$ used a gaze-contingent paradigm to explore whether adults with prosopagnosia process faces holistically or analytically. Their paradigm manipulated the manner 


\section{RUNNING HEADER: PROSOPAGNOSIA FIRST FIXATIONS}

with which participants can match faces, by guiding the processing of features in either an analytic or holistic manner. During the experiment, a two-alternative forced choice paradigm was used, with face stimuli. During a third of the trials, participants could freely process the faces in full. However, in the remaining two thirds of trials, participants' eye movements were used to limit perception of the faces in one of two ways, which were designed to simulate either analytic or holistic processing (see Figure 1). During analytic-type trials, a gaze-contingent window revealed only a small area of the face (such as one facial feature) whilst the face falling outside the window was masked. Whereas for holistic-type trials, a mask replaced the window, so that features could not be focussed upon. This forced participants to rely on the whole face beyond just the fixated feature.

Van Belle and colleagues' found that face recognition expertise was not the product of sequential featural processing, but instead, may be the product of the ability to view individual features of the face all at once. These results indicated that holistic processing aids face recognition, and this may be disrupted in impaired face processing; i.e. in prosopagnosia. However, for the current study we were primarily interested in the first fixation on a face. We used the Van Belle et al (2010) paradigm so that we could explore whether different viewing conditions could affect performance within-subjects (condition: full, window, mask), but also between-groups (prosopagnosia and controls). Also, this design would allow us to discover whether first fixations could be linked to face recognition, but also whether it was disrupted by holistic or analytic gazecontingent manipulations. This is the secondary focus of the current study. Van Belle et al (2010) found that a foveal mask was more disruptive to face recognition than a peripheral mask. Based on this result, they argued that participants employed a more holistic approach to face recognition. Therefore, by using the same viewing conditions, we could explore whether holistic processing begins with a first fixation to an optimal area. Relative to controls, we predicted that prosopagnosia cases will be atypical in first fixations, and that these fixations will also be atypically affected by 
Belle et al, 2010).

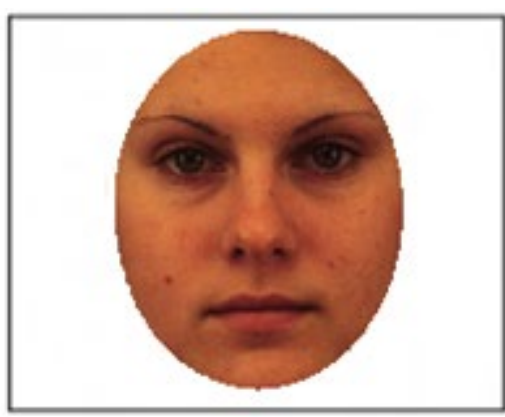

Full view

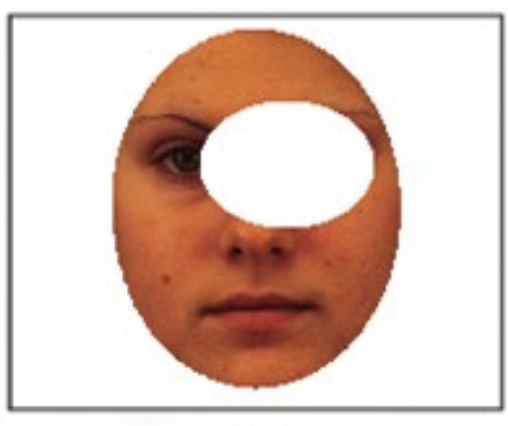

mask

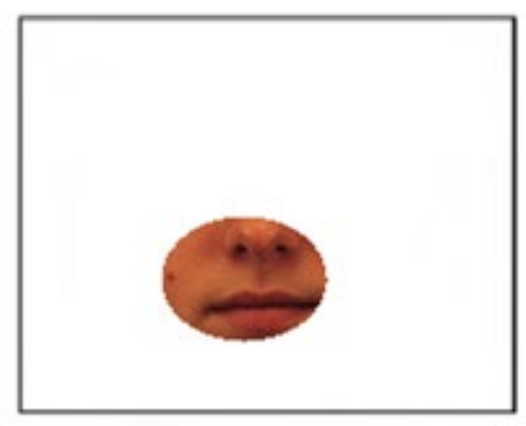

window

Figure 1. Illustration of the different viewing conditions in the experiment. The size of the window/mask was adjusted to reveal/cover roughly one main internal feature of the face at a time only. The position of the mask/window was synchronised with the observer's fixation position.

\section{METHOD}

\subsection{Participants}

There were 22 participants in the study: 5 people with developmental prosopagnosia (mean age $=$ 27.33; 3 males) and 17 non-prosopagnosia controls (mean age $=21.28 ; 3$ males). All participants were Swansea University students and all were British Caucasians to avoid any potential other race effects (Burns et al., 2019; Bate et al., 2018; Estudillo et al., 2019). Participants with prosopagnosia were paid for their time and control participants received subject-pool participation credit. All adults with prosopagnosia confirmed their regular difficulties with faces, a fundamental trait of prosopagnosia, in a short interview with one of the authors in addition to neuropsychological testing (see Table 1); FFT (Famous Faces Test; Duchaine \& Nakayama, 2005); CFPTu/i (Cambridge Face Perception Task upright / inverted; Duchaine et al., 2007); CFMTu/i (Cambridge Face Memory Task upright / inverted; Duchaine \& Nakayama, 2006b); RMT-f(Recognition Memory Test-faces; Warrington, 1984); Eyes (Reading the Mind in the Eyes task; Baron-Cohen, Jolliffe, Mortimore, \& Robertson, 1997); AQ (Autism Spectrum Quotient; 
Baron-Cohen, Wheelwright, Skinner, Martin, \& Clubley, 2001); GNT (Graded Naming Test;

McKenna \& Warrington, 1980); BORB (Birmingham Object Recognition Battery; Riddoch \&

Humphreys, 1993 - two difficult subtests used from test 10, 64 objects in total), RMT-w

(Recognition Memory Test-words; Warrington, 1984). Norms for these tests are reported in Table

1 and were taken from the aforementioned papers or from data collected by our own lab. To be classed as impaired, we required our adults with prosopagnosia to be impaired more than 2 standard deviations away from the control mean on the FFT and CFMT as per prior work (Bate et al., 2014; Burns et al., 2018; Burns et al., 2014; Burns et al., 2017a, Burns et al., 2017b). The controls did not complete the neuropsychological battery of tests, but all had to confirm no trouble recognising faces (the fundamental trait of prosopagnosia): e.g., difficulties not recognising celebrities, having problems recognising familiar people they should identify, such as friends, coworkers and family members.

Table 1. Developmental prosopagnosia case scores on neuropsychological test battery. 190

\begin{tabular}{lllllll} 
& DP1 & DP2 & DP3 & DP4 & DP5 & $\begin{array}{l}\text { Cut-off, for } \\
\text { impairment }\end{array}$ \\
\hline Age & 20 & 38 & 20 & 21 & 34 & \\
Sex & F & M & M & F & M & \\
Face testing & & & & & & \\
Famous Faces Test & $10 / 35$ & $12 / 35$ & $22 / 35$ & $13 / 35$ & $24 / 35$ & $<29 / 35$ \\
CFPTu & $64 / 144$ & $84 / 144$ & $60 / 144$ & $48 / 144$ & $53 / 144$ & $>65 / 144$ \\
CFPTi & $52 / 144$ & $74 / 144$ & $60 / 144$ & $40 / 144$ & $48 / 144$ & $>92 / 144$ \\
CFMTu & $28 / 72$ & $28 / 72$ & $40 / 72$ & $37 / 72$ & $36 / 72$ & $<42 / 72$ \\
CFMTi & $16 / 72$ & $34 / 72$ & $30 / 72$ & $39 / 72$ & $37 / 72$ & $<28 / 72$ \\
RMT-f & $35 / 50$ & $28 / 50$ & $34 / 50$ & $34 / 50$ & $36 / 50$ & $<36 / 50$ \\
Autism Screening & & & & & & \\
Eyes & 29 & 22 & 26 & 25 & 26 & $<19 / 25$ \\
ASQ & 24 & 28 & 25 & 25 & 12 & $>32 / 50$ \\
Non-face testing & & & & & & \\
GNT & $16 / 30$ & $19 / 30$ & $20 / 30$ & $25 / 30$ & $22 / 30$ & $<12 / 30$ \\
BORB & $52 / 64$ & $53 / 64$ & $56 / 64$ & $62 / 64$ & $51 / 64$ & $<23 / 64$ \\
RMT-w & $36 / 50$ & $47 / 50$ & $46 / 50$ & $41 / 50$ & $45 / 50$ & $<35 / 50$ \\
\hline
\end{tabular}

FFT (Famous Faces Test; Duchaine \& Nakayama, 2005); CFPTu/i (Cambridge Face Perception Task upright / inverted; Duchaine et al., 2007); CFMTu/i (Cambridge Face Memory Task upright / inverted; Duchaine \& Nakayama, 2006b); RMT-f 
(Recognition Memory Test-faces; Warrington, 1984); Eyes (Reading the Mind in the Eyes task; Baron-Cohen, Jolliffe, Mortimore, \& Robertson, 1997); AQ (Autism Spectrum Quotient; BaronCohen, Wheelwright, Skinner, Martin, \& Clubley, 2001); GNT (Graded Naming Test; McKenna \& Warrington, 1980; Warrington, 1997); BORB (Birmingham Object Recognition Battery; Riddoch \& Humphreys, 1993 two difficult subtests used from test 10, 64 objects in total), RMT-w (Recognition Memory Test-words; Warrington, 1984).

\subsection{Stimuli}

Both the stimuli and the face recognition task were obtained from Van Belle et al. (2010) and followed the same protocol. The task involved the delayed matching of photographs of unknown adult faces: a face was presented followed by a side-by-side presentation of photographs of two faces; one of which was the target that previously appeared in the trial, the other a foil. Note that the matching faces, were photographed at different moments in time, so were slightly different. The participant's task was to identify the target face.

Stimuli were displayed on a 22 " CRT computer monitor at a viewing distance of $55 \mathrm{~cm}$ with a spatial resolution of 1280 by 1024 pixels and a refresh rate of $100 \mathrm{~Hz}$. The height of the faces was $15^{\circ}$, the distance between the inner borders of the faces was approximately $10^{\circ}$, and the elliptical window and mask subtended $8.5^{\circ}$ horizontally by $6.5^{\circ}$ vertically. The stimulus set contained 10 male and 10 female faces (KDEF database; Lundqvist, Flykt, \& Öhman, 1998), each of which had external features cropped, but head shape largely preserved. The faces were randomly combined in pairs of two males or two females. Stimulus display and response registration were handled by an Intel Pentium 4 PC. Eye movements were recorded using SR Research EyeLink 1000 eye tracker at a sampling rate of $1000 \mathrm{~Hz}$ and with gaze position error smaller than $0.75^{\circ}$. Eye movements were recorded monocularly, with the dominant eye being determined using the Miles test (Roth, Lora \& Heilman, 2002). Head movement was restricted by a chin rest. 
212 The trial procedure is presented in Figure 2. A drift correction with a central fixation cross was

213 followed by the presentation of a blurred face, which was the grey-scale average image of all

214 faces, indicating the position of the reference face and a fixation cross on the left of that face.

215 Participants were instructed to fixate on the fixation cross. Upon steady fixation by the participant,

216 the cross disappeared. From the moment the participant fixated on the blurred face, it changed

217 into the reference face, which participants were instructed to memorise for 4 seconds. After this

218 the participant was prompted to return their gaze to the centre of the screen and two faces were

219 then presented, one on each side of the screen. The participant could freely explore both faces

220 during an unrestricted time period.
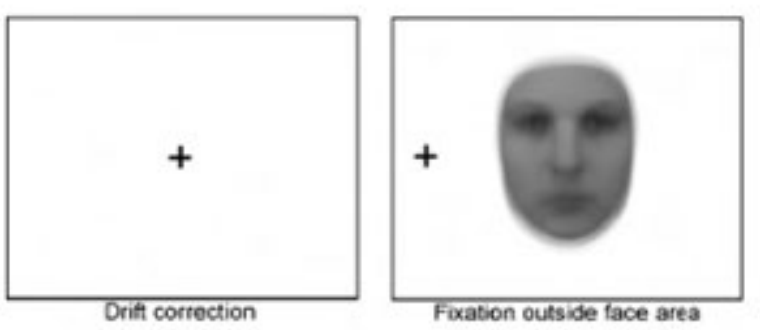

Foxation outside face area

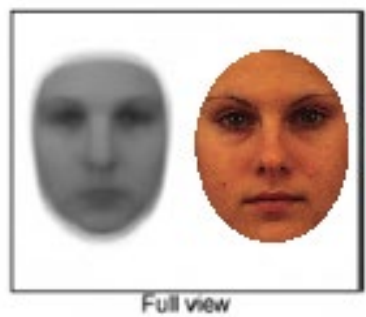

Fuil view
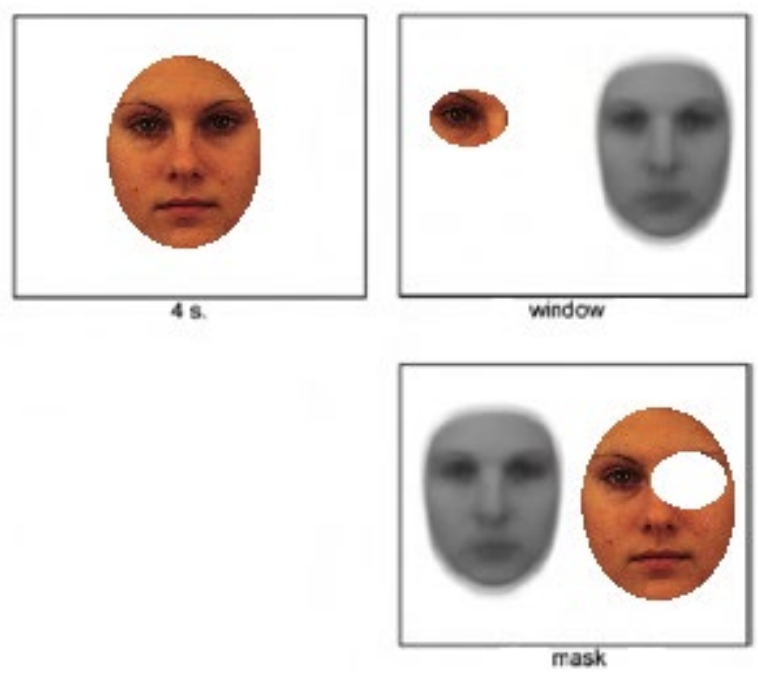

Figure 2. Procedure of a trial. The greyscale face displayed is the average of all faces, this is displayed when the observer does not fixate on the face. In all conditions, the non-fixated face was always replaced by the blurry average face. In the mask and window, the fixated face was covered by the window or mask. 


\section{RUNNING HEADER: PROSOPAGNOSIA FIRST FIXATIONS}

In one third of the trials, the faces were completely visible (full view). In another third of the trials, a gaze-contingent mask covered the fixated feature in the central part of the visual field (mask condition). In the remaining third of the trials, only the fixated feature in the central part of the visual field was visible through a limited spatial window (window condition). The mask/window covered/revealed roughly one feature of the face at a time (eye, nose, or mouth), although it was large enough to cover/reveal the whole eye-eyebrow combination in the mask/window conditions, respectively.

During the exploration of the pair of faces, the face that was not fixated upon by the participant was replaced by the average face (Figure 2), in order to provide a reference frame for saccade planning to the face in all viewing conditions. Furthermore, this way, the amount of information from one face during the exploration of the other face was similar in all three viewing conditions. The matching response was provided by pressing the left or right keyboard key.

The experiment was subdivided into 9 blocks, each consisting of 27 trials, 9 for each of the 3 viewing conditions (for 81 trials/condition in total). The order of the viewing conditions within each block was randomised and the participant was unaware of the type of viewing condition during the exploration of the reference face.

\section{RESULTS}

Our primary interest was the first fixation made on each face within each of the trials i.e. the first fixation on the left face and then the first fixation on the right face. There were three trial-types (Full, window, and mask). Each trial was preceded by a reference face. Therefore, we obtained first fixation information for four different types of faces. For each of the faces we computed the $\mathrm{x}$ and $\mathrm{y}$ coordinates of the centre-point between the eyes. We measured in degrees $\left(^{\circ}\right)$ how far the first fixation was from the centre-point between the eyes, along $\mathrm{x}$ and $\mathrm{y}$ coordinates. We were then able to compare these $\mathrm{x}$ and $\mathrm{y}$ coordinates to the first fixation on the face made by each participant. 


\section{RUNNING HEADER: PROSOPAGNOSIA FIRST FIXATIONS}

251

252

253

254

255

256

257

258

259

260

261

We predicted that the control participants would consistently make a first fixation toward the optimal face recognition location on the face, despite the viewing condition (in terms of average first fixation location and variation in first fixation location: see Peterson \& Eckstein, 2012). However, we anticipated that people with prosopagnosia would make first fixations on the face in an atypical manner. Note, as would be expected, people with prosopagnosia and controls differed significantly on the task in terms of accurately recognising the faces $(F(1,20)=18.822$; $\mathrm{p}<.005)$ and reaction time $(\mathrm{F}(1,20)=18.162 ; \mathrm{p}<.005$ : see Table 2$)$. However, of primary interest was the first fixation toward each face.

Table 2. Accuracy and reaction time (seconds) data for the three trial types for controls and people with prosopagnosia. Parenthesis contain the standard deviation.

\begin{tabular}{llcll} 
& \multicolumn{2}{c}{ Accuracy } & \multicolumn{2}{c}{ Reaction Time } \\
& Control & DP & \multicolumn{1}{c}{ Control } & DP \\
\hline Full & $1(.02)$ & $.89(.23)$ & $1.71(.58)$ & $3.0(1.51)$ \\
Mask & $.97(.04)$ & $.85(.30)$ & $2.25(.77)$ & $5.32(3.10)$ \\
Window & $.91(.07)$ & $.74(.44)$ & $3.32(1.15)$ & $7.17(3.39)$
\end{tabular}

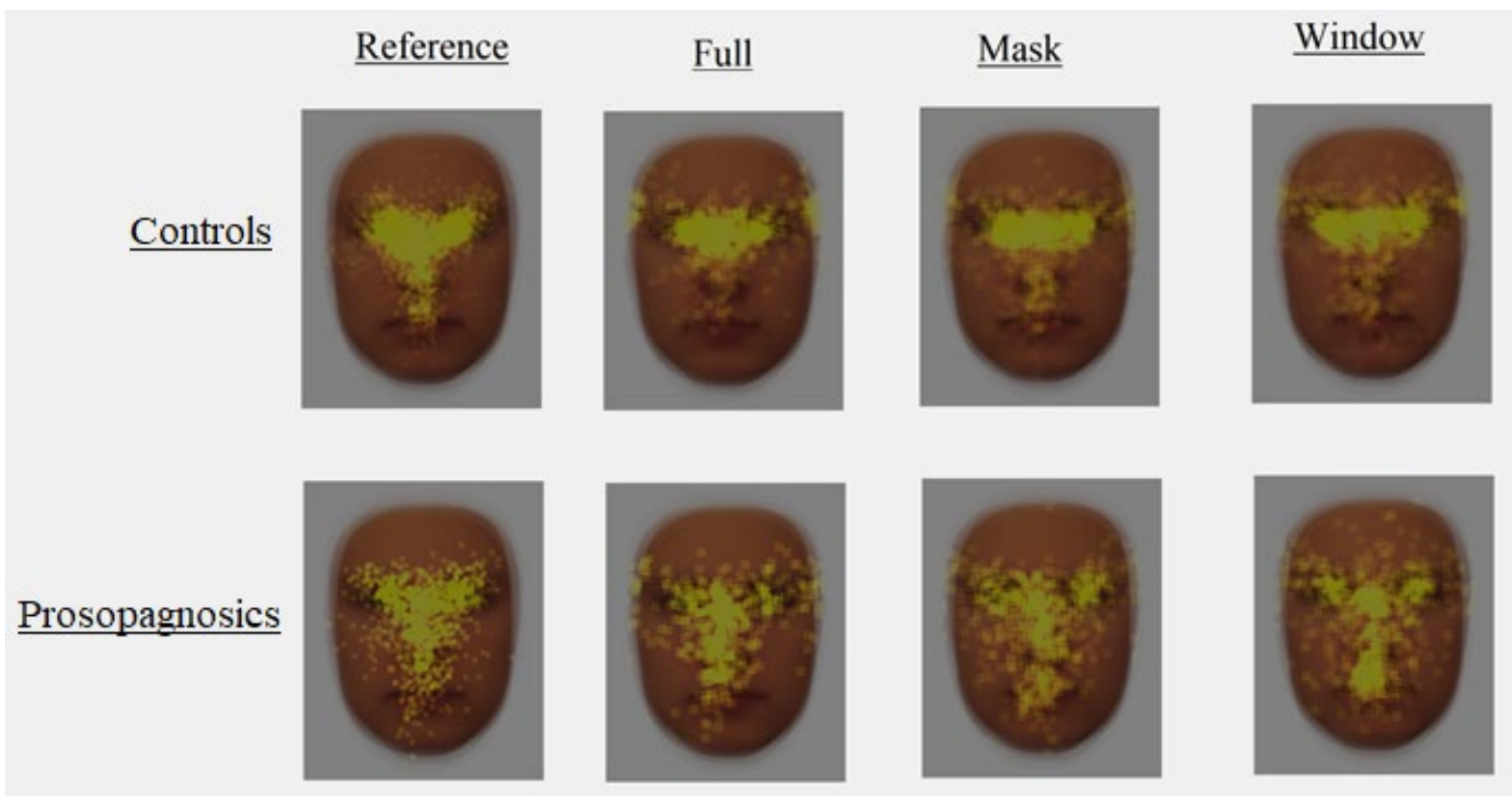

Figure 3. Heatmaps of all first fixation points. Control participant $(\mathrm{N}=17)$ first fixations are on the top, and prosopagnosia participants $(\mathrm{N}=5)$ are on the bottom. The prosopagnosia participants are more heterogeneous in where their first fixations land, particularly on the y axis. The face-types are all presented separately. 
Figure 3 demonstrates the heat maps of first fixations across all trials, with Figure 4 illustrating the mean first fixations for the control participants and each of the adults with prosopagnosia. Across the different conditions, the control participants were consistently making the eyes. However, the prosopagnosia group's first fixations were much less focussed. Although, the prosopagnosia cases' first fixations do appear similar to controls in terms of the horizontal plane, it appears that there is a larger spread of first fixations along the vertical plane. We therefore analysed $\mathrm{x}$ and $\mathrm{y}$ coordinates separately.

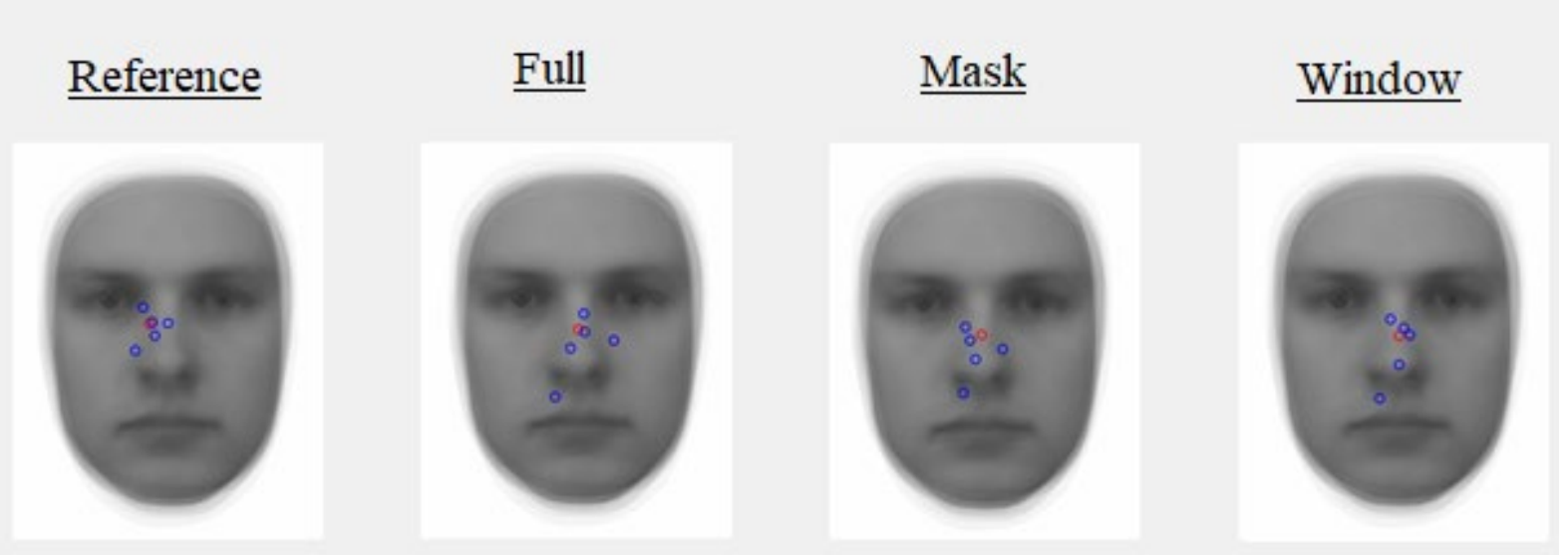

Figure 4. Average first fixation points from all trials for controls (red) and the individual people with prosopagnosia (blue). The face-types are reference, full, mask and window.

As first fixations in the adults with prosopagnosia could have been atypically above or below the centre-point from the eyes, it may be inappropriate to average our participants' data together (i.e., Figure 4). This is because we would not be able to recognise the consistency, or inconsistency, with which the adults with prosopagnosia are initially fixating upon the faces (i.e., the trial by trial fixation variability). It may be more appropriate to instead look at the variance within each participant for first fixation y coordinates, as this would crudely index the heterogeneity with which they first looked at a face. For example, if control participants are highly consistent in their first fixations, they will have very little variance. Prosopagnosia cases may first fixate in an incredibly heterogeneous fashion, thereby suggesting that they do not have a consistent 
pattern with which to initially focus on a face or be distracted by other features. This is borne out by inspection of Figure 3 .

To examine any possible group differences in this heterogeneity, we performed a $2 \times 4$ repeated measures ANOVA on participants' first fixations' standard deviations of the y-axis coordinates in degrees $\left(^{\circ}\right)$ from the centre point between the eyes, using factors of Group Group $[\mathrm{F}(1,20)=14.131 ; \mathrm{p}=.001]$. This latter effect was driven by prosopagnosia cases' increased variability along the y axis for their first fixation (see Figure 5). There was also a significant interaction between Face-type and Group $[\mathrm{F}(3,60)=4.420 ; \mathrm{p}=.007]$. Subsidiary comparisons showed that prosopagnosia cases' y co-ordinate standard deviations ( mean $=2.08^{\circ}$; $\mathrm{SD}=.55)$ were found to vastly differ from the control participants' (mean $\left.=1.23^{\circ} ; \mathrm{SD}=.41\right)$ for full trials $[\mathrm{t}(20)=-3.842 ; \mathrm{p}=.001]$, window trials $\left(\mathrm{DP}\right.$ mean $=2.36^{\circ} ; \mathrm{SD}=.68$; Control mean $=$ $\left.1.38^{\circ} ; \mathrm{SD}=.49 ; \mathrm{t}(20)=-3.595 ; \mathrm{p}=.002\right]$, and mask trials $\left(\mathrm{DP}\right.$ mean $=2.17^{\circ} ; \mathrm{SD}=.50 ;$ Control mean $\left.=1.48^{\circ} ; \mathrm{SD}=.57 ; \mathrm{t}(20)=-2.428 ; \mathrm{p}=.025\right]$. By contrast, no group differences were found in the reference condition $(\mathrm{DP}$ mean $=1.02 ; \mathrm{SD}=.21$; Control mean $=.86 ; \mathrm{SD}=.21 ; \mathrm{t}(20)=-$ lack of power, rather than due to the absence of an effect $\left(\mathrm{BF}_{10}=.906\right){ }^{1}$

Note, we also performed $2 \times 4$ repeated measures ANOVA on the standard deviations of the $\mathrm{x}$-axis coordinates in degrees $\left(^{\circ}\right)$, using factors of Group (DP, control) and Face-type

\footnotetext{
${ }^{1}$ Note, we explored the effect of age and sex. Age was not found to be associated with y coordinate SD in either the controls (reference: $\mathrm{r}(15)=.240 ; \mathrm{p}=.354$; full: $\mathrm{r}(15)=.450 ; \mathrm{p}=.07$; window: $\mathrm{r}(15)=.385 ; \mathrm{p}=.127$; mask: $\mathrm{r}(15) .240 ; \mathrm{p} .354$ ) nor prosopagnosia (reference: $\mathrm{r}(3)=.003 ; \mathrm{p}=.989$; full: $\mathrm{r}(3)=.404 ; \mathrm{p}=.50$; window: $\mathrm{r}(3)=.330 ; \mathrm{p}=.588$; mask: $\mathrm{r}(3)=.058 ; \mathrm{p}=.927)$. Similarly, males and females did not differ in performance on the task in terms of accuracy or $y$ coordinates ( $p>$.05). Further, we conducted a series of t-tests between a group of age-matched controls (which included the five oldest controls) compared to the five prosopagnosia cases. These groups were found not to differ in terms of age $(\mathrm{t}(8)=.580 ; \mathrm{p}=.578)$. However, the groups did differ in terms of y coordinate variance for the full condition $(\mathrm{t}(8)=2.448 ; \mathrm{p}=.040)$, window condition $(\mathrm{t}(8)=2.332 ; \mathrm{p}=.049)$, and marginally the mask condition $(\mathrm{t}(8)=1.996 ; \mathrm{p}=.081)$ and reference $(\mathrm{t}(8)=1.719 ; \mathrm{p}=.124)$. This suggests that there is strong evidence that age and sex did not affect performance.
} 


\section{RUNNING HEADER: PROSOPAGNOSIA FIRST FIXATIONS}

(reference, full, mask, window). Levene's test indicated equal variances (all p's $>.05$ ). It was observed that there was a main effect of Face-type $[F(3,60)=21.154 ; p<.0005]$. However, we did not observe a significant main effect of Group $\left[\mathrm{F}(1,20)=.007 ; \mathrm{p}=.936\right.$; $\left.\mathrm{BF}_{\text {INCLUSION }}=.34\right]$ nor significant interaction $\left[\mathrm{F}(3,60)=.921 ; \mathrm{p}=.436 \mathrm{BF}_{\text {INCLUSION }}=.39\right]$. This demonstrates that adults with prosopagnosia did not demonstrate increased variability for $\mathrm{x}$ axis co-ordinates and this interpretation is supported by the Bayesian analysis.

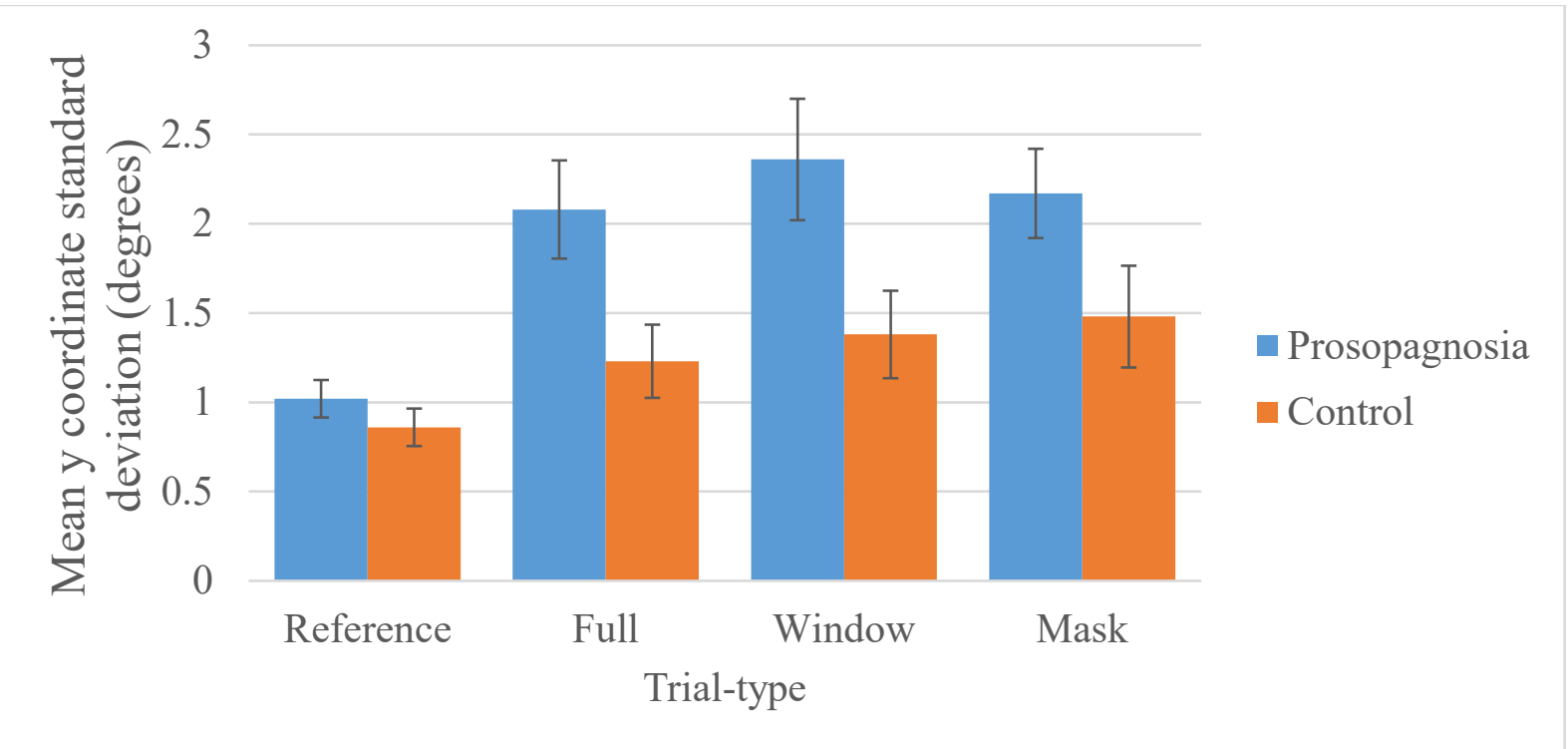

Figure 5. The average first fixation standard deviations of the y axis coordinates in degrees $\left({ }^{\circ}\right)$ for controls (orange) and the people with prosopagnosia (blue) for each trial-type reference, full, mask and window. The prosopagnosia group were atypically heterogeneous as to where their first fixations landed on faces' vertical planes in all conditions barring the Reference condition (i.e., left-most bars) where they were memorising the face. Error bars show standard error.

Next, we used the Crawford adjusted single-samples t-test (Crawford \& Garthwaite, 2002) in order to compare each prosopagnosia participant separately to the controls. Table 3 demonstrates that four of the five people with prosopagnosia had atypical y coordinate first fixation standard deviations in degrees $\left(^{\circ}\right)$ during the Full trials-types, which likely reflects their typical strategies when viewing a face. This suggests the majority of prosopagnosia cases might have subtle problems in performing optimal first fixations, and contrasts with other eye tracking 
data which suggests it is only the most severe of prosopagnosia cases that have atypicalities in in the Mask condition and two cases in the Window condition atypical. To explore this further, we considered where people with prosopagnosia fell on a continuum which included controls ranging from the lowest SD to the highest SD (see figure 6). Control y coordinates for the reference faces ranged from $.55^{\circ}$ to $1.2^{\circ}$, for full face trials from $.53^{\circ}$ to $1.97^{\circ}$, for window face trials from $.68^{\circ}$ to $2.19^{\circ}$, and mask face trials from $.56^{\circ}$ to $2.63^{\circ}$. Therefore, some of the control participants had a higher y coordinate SD than some of the prosopagnosia participants (see figure

6). This indicates that the first fixation location is not always optimum in control participants too.

But the prosopagnosia cases' (particularly DP4 and DP5) first fixations were typically amongst the furthest away from the optimum location.

Table 3. The standard deviation of first fixations y-coordinates away from the centre-point between the eyes for individual prosopagnosia cases (z-score), and the average of the standard deviation for all control participants (SD). Note that these are degrees away from the centre-point and not degrees away from the optimal place of slightly to the left of the centre-point, as observed by Peterson $\&$ Eckstein (2012). Also note, * denotes $<.05$ level of significance; ** denotes

Bonferroni corrected level of significance of $<.013$

\begin{tabular}{lrrrr} 
& Reference & Full & Window & Mask \\
\hline Control (SD) & $.86(.21)$ & $1.23(.41)$ & $1.38(.49)$ & $1.48(.57)$ \\
DP1 (z-score) & $.91(.21)$ & $1.15(-.2)$ & $1.40(.04)$ & $2.02(1.0)$ \\
DP2 (z-score) & $.87(.05)$ & $2.28^{* *}(3.2)$ & $2.18(1.6)$ & $1.85(2.0)$ \\
DP3 (z-score) & $.84(-.1)$ & $2.09 *(2.1)$ & $2.72^{* *}(2.7)$ & $1.59(.20)$ \\
DP4 (z-score) & $1.25^{*}(1.9)$ & $2.39^{* *}(2.9)$ & $3.23^{* *}(3.8)$ & $2.73^{*}(2.2)$ \\
DP5 (z-score) & $1.25^{*}(1.9)$ & $2.51^{* *}(3.2)$ & $2.26^{*}(1.8)$ & $2.64^{*}(2.0)$
\end{tabular}

\begin{tabular}{|c|c|c|c|c|c|c|c|c|c|c|c|c|c|c|c|c|c|c|c|c|c|}
\hline \multirow[b]{2}{*}{ Reference } & \multicolumn{5}{|c|}{ Low $S D$} & & & & & & & & & & & & & \multicolumn{3}{|c|}{ High SD } & \multirow[b]{2}{*}{ DP5 DP4 } \\
\hline & $\mathrm{C}$ & C & C & $\mathrm{C}$ & C & C & $\mathrm{C}$ & C & C & DP3 & C & DP2 & C & DP1 & C & C & C & C & C & $\mathrm{C}$ & \\
\hline Full & $\mathrm{C}$ & C & C & $\mathrm{C}$ & C & C & $\mathrm{C}$ & C & C & DP1 & C & C & C & C & C & C & C & C & DP3 & DP2 & DP4 DP5 \\
\hline Window & $\mathrm{C}$ & C & C & $\mathrm{C}$ & $\mathrm{C}$ & C & $\mathrm{C}$ & C & C & $C$ & DP1 & C & C & C & C & C & C & DP2 & C & DP5 & DP3 DP4 \\
\hline Mask & $\mathrm{C}$ & C & C & $\mathrm{C}$ & $\mathrm{C}$ & C & $\mathrm{C}$ & C & C & $C$ & C & C & DP3 & $C$ & DP2 & DP1 & C & C & $\mathrm{C}$ & C & DP5 DP4 \\
\hline
\end{tabular}


RUNNING HEADER: PROSOPAGNOSIA FIRST FIXATIONS

Figure 6. The standard deviation continuum of y coordinates for people with prosopagnosia and controls on the different face-types.

\section{DISCUSSION}

Previous research has found that just to the left of the centre of the face is the optimal location for first fixations during face recognition (Hsiao \& Cottrell, 2008; Peterson \& Eckstein, 2012). It has been speculated that this position may be the optimal place for holistic processing of the entire face to occur (Hsiao \& Cottrell, 2008; Peterson \& Eckstein, 2012). Evidence suggests that people with prosopagnosia are impaired in holistic processing (Avidan, Tanzer, \& Behrmann, 2011; Jansari et al. 2015). Indeed, interventions designed to improve holistic processing can lead to improved face processing in some people with prosopagnosia (DeGutis, Cohan, \& Nakayama, 2014). Bobak et al. (2017) observed that the nose (a region broadly analogous to the optimal place for holistic processing) had decreased dwell time within prosopagnosia cases potentially indicating decreased capability for holistic processing. However, only two fixations may be required for face recognition (Hsiao \& Cottrell, 2008) so dwell time may not be the most precise measure of holistic-type processing.

Here, we instead looked at first fixations and found evidence that people with prosopagnosia, as a group, exhibit atypically heterogenous first fixations when landing on a face's vertical plane. This occurred when asked to recognise a face, and also when face recognition was disrupted by our gaze contingent manipulation. While the first fixations were not significantly atypical on the reference faces (i.e., during memorising), two of five of our prosopagnosia cases were severely impaired. Moreover, none of the prosopagnosia cases were homogenous in their first fixations much above the mean of the control group, in the reference condition or any other. This suggests that while some prosopagnosia cases can perform within the control range, as a group, they may never attain levels of consistency beyond the control group's midrange. This is remarkably similar to the perceptual deficits that prosopagnosia cases as a group exhibit: even 
RUNNING HEADER: PROSOPAGNOSIA FIRST FIXATIONS

though many can score within the bottom half of the control range, they never perform to any great extent beyond the neurotypical mean (Biotti, Gray \& Cook, 2019).

Atypical heterogeneity of first fixations in developmental prosopagnosia may be due to a number of different problems that these individuals suffer from. One such hypothesis is that impaired holistic perception may result in the atypical viewing patterns we observed. This interpretation is based upon the possibility that an optimal first fixation just below the eyes may enable the parallel processing of multiple facial features parafoveally, i.e. the eyes, nose, mouth, and the distances between them are processed in parallel as an integrative whole. If their ability to utilise holistic perception is non-existent, or at least quantitatively impaired, then there is little motivation to consistently land within this narrow vertical plane where holistic perception is most efficiently utilised. Instead, prosopagnosia cases may fixate more frequently on broader features present within the face, to aid whatever residual face processing abilities they have; i.e., picking up on whatever distinctive cues they can detect (Burns et al., 2014), and/or utilising featural processing more frequently as a remedial technique. Alternatively, they could have a problem at landing first fixations consistently within this 'optimal' vertical window, which then leads to a failure to effectively utilise holistic perception. Future work will be required to explore these possibilities.

In addition, our data supported the findings of Peterson \& Eckstein (2012), in that participants without face recognition problems made a first fixation toward the eye region during face recognition. This was observed despite our experimental attempts at disrupting face recognition by using two different gaze contingency trial-types (mask or window: Figure 3). Note Van Belle et al (2010) found that foveal mask was more disruptive to face recognition than the peripheral mask. Based on this result, they argued that participants employed a more holistic approach to face recognition. Within the current study we observed that the scanning patterns of the individuals with developmental prosopagnosia were equivalent across the three conditions. 
RUNNING HEADER: PROSOPAGNOSIA FIRST FIXATIONS

397 Therefore, it is not clear to what extent we can infer whether they were employing holistic and/or non-holistic strategies. However, the equivalence between the conditions may indicate that holistic and/or non-holistic strategies for face perception occurs in subsequent fixations rather than first fixations. the use of two new conditions to disrupt face recognition: window and mask - with the largest degree differences away from the centre region of the eyes (i.e. poorer performance) were found for the restricted viewing conditions for controls. [2] The results also indicate that prosopagnosia is associated with viewing faces at sub-optimal locations. Because participants impaired in face recognition demonstrate different first fixation locations, this may imply that a failure to develop an automatic orientation to this location could be contributing to poorer face recognition. The results imply that first fixation differences in face recognition could either be a cause or effect of prosopagnosia, and thus our findings indicate the need for further exploration of these divergences in eye fixation patterns in cases of prosopagnosia. Peterson \& Eckstein (2012) found that forcing participants to maintain gaze points away from preferred point of fixation degraded perceptual performance. DeGutis, Cohan, and Nakayama (2014) found evidence to suggest that using interventions designed to encourage holistic processing of faces improved face recognition for people with prosopagnosia. Would these findings therefore imply that if people with prosopagnosia were forced to attend to the optimal first fixation location (and therefore encourage holistic processing), their face recognition ability would improve? The implications are striking: could attentional retraining toward optimal face recognition regions improve face recognition performance for prosopagnosia? Peterson and colleagues (2019) found that such forced viewing away from an individual's own looking preference (e.g., if they prefer to look at the mouth, then they are forced to look at the eyes) results in a decline in face processing performance. This suggests shifting fixations will not necessarily improve face processing abilities in prosopagnosia, 
RUNNING HEADER: PROSOPAGNOSIA FIRST FIXATIONS

however, it might accelerate improvement when a training paradigm such as DeGutis and colleagues' (2013) is employed.

Atypicalities of first fixations were only found along the y plane of the face and not the $x$ plane within the prosopagnosia group. They showed increased variability in terms of the vertical position of their first fixation but not horizontal first fixation position. This may indicate that people with prosopagnosia have intact first fixation positional allocation in terms of limiting eye movement to a notional vertical centre line down the face. However, in terms of their vertical first fixation location, the people with prosopagnosia were more likely to look at features below the centre-point between the eyes, for example, the nose and the mouth, but also more likely to look above the eyes (potentially toward the hairline). This behaviour may represent a viewing pattern for face recognition which involves differentiating faces based upon distinctive features, such as hair styles or distinctive noses or mouths (see Kress \& Daum, 2003). These results may therefore imply that when recognising faces, a person with prosopagnosia is more likely to look up and down a face to recognise it rather than left or right. This might be because there may be fewer distinctive features which would aid face identification to be found to the left and/or right side of a face (see Bobak, et al., 2017). There was a degree of overlap between the controls and people with prosopagnosia in terms of the y coordinates. Further, the results imply that some of the control participants had more y variability in first fixations than some of the people with prosopagnosia. Also, there may be individual differences in first fixations within participants (cf Peterson \& Eckstein, 2013), so there is no clear cut-off scores between people with prosopagnosia and controls. It is possible that the results represent a continuum of ability to holistically process a face in a single fixation, with control participants typically able to do this, with some people with prosopagnosia consistently less able to do this, whilst there is a grey area in between. Although note, people with prosopagnosia were all typically amongst the participants less likely to fixate toward the neurotypical optimum location. Therefore, the results appear to suggest a qualitative 


\section{RUNNING HEADER: PROSOPAGNOSIA FIRST FIXATIONS}

rather than a quantitative shift for the adults with prosopagnosia. It is apparent that further research is required regarding first fixation location.

It is also worth reflecting on why the current results differ so greatly from those reported by Peterson et al (2019). They found no differences in first fixations between people with prosopagnosia and controls, whilst we did find clear differences. This discrepancy in findings may be due to methodological differences between the two studies; for example, they tested prosopagnosia cases with celebrity faces, emotional unfamiliar faces, and cars. By contrast, we used unfamiliar neutral faces. Future work will be required to confirm if emotion and face familiarity can therefore account for these differences. .

In conclusion, it was observed that people with prosopagnosia demonstrate a difference from controls in y coordinates when recognising faces. This difference in orienting of attention may contribute to poorer face recognition abilities. The question of whether this is a cause or effect of prosopagnosia is beyond the scope of this paper, but points to a potential future avenue for further work. In particular, we hope that this research may provide guidance for further work that may focus on utilising attentional retraining to remediate people with prosopagnosia with face recognition.

\section{Acknowledgements}

Thanks to G. Van Belle for sharing their experiment with us. Thanks to I. Reppa, and S. Johnston for their input on initial project development. Thanks to J. Leakey and C. Clarke for their input also.

\section{References}

Arcaro, M. J., Schade, P. F., Vincent, J. L., Ponce, C. R., \& Livingstone, M. S. (2017). Seeing faces is necessary for face-domain formation. Nature neuroscience, 20(10), 1404. 
Arizpe, J., Walsh, V., Yovel, G., \& Baker, C. I. (2017). The categories, frequencies, and stability of idiosyncratic eye-movement patterns to faces. Vision research, 141, 191-203.

Avidan, G., Tanzer, M., \& Behrmann, M. (2011). Impaired holistic processing in congenital prosopagnosia. Neuropsychologia, 49(9), 2541-2552.

Baron-Cohen, S., Jolliffe, T., Mortimore, C., \& Robertson, M. (1997). Another advanced test of theory of mind: Evidence from very high functioning adults with autism or Asperger syndrome. Journal of Child psychology and Psychiatry, 38(7), 813-822.

Baron-Cohen, S., Wheelwright, S., Skinner, R., Martin, J., \& Clubley, E. (2001). The autismspectrum quotient (AQ): Evidence from asperger syndrome/high-functioning autism, malesand females, scientists and mathematicians. Journal of autism and developmental disorders, 31(1), 517.

Bate, S., Bennetts, R., Hasshim, N., Portch, E., Murray, E., Burns, E., \& Dudfield, G. (2019). The limits of super recognition: An other-ethnicity effect in individuals with extraordinary face recognition skills. Journal of Experimental Psychology: Human Perception and Performance, 45(3), 363.

Bate, S. \& Tree, J. J. (2017). The definition and diagnosis of developmental prosopagnosia. Quarterly Journal of Experimental Psychology, 70, 2, 193-200.

Bate, S., Cook, S. J., Duchaine, B., Tree, J. J., Burns, E. J., \& Hodgson, T. L. (2014). Intranasal inhalation of oxytocin improves face processing in developmental prosopagnosia. Cortex, 50, 5563.

Bate, S., \& Cook, S. J. (2012). Covert recognition relies on affective valence in developmental prosopagnosia: Evidence from the skin conductance response. Neuropsychology, 26(5), 670.

Bate, S., Bennetts, R., Mole, J. A., Ainge, J. A., Gregory, N. J., Bobak, A. K., \& Bussunt, A. (2015). Rehabilitation of face-processing skills in an adolescent with prosopagnosia: Evaluation of an online perceptual training programme. Neuropsychological Rehabilitation, 25(5), 733-762.

Bate, S., Haslam, C., Jansari, A., \& Hodgson, T. L. (2009). Covert face recognition relies on affective valence in congenital prosopagnosia. Cognitive Neuropsychology, 26(4), 391-411.

Bate, S., Haslam, C., Tree, J. J., \& Hodgson, T. L. (2008). Evidence of an eye movement-based memory effect in congenital prosopagnosia. Cortex, 44(7), 806-819. 
Behrmann, M., \& Avidan, G. (2005). Congenital prosopagnosia: face-blind from birth. Trends in cognitive sciences, 9(4), 180-187.

Bennetts, R. J., Butcher, N., Lander, K., Udale, R., \& Bate, S. (2015). Movement cues aid face recognition in developmental prosopagnosia. Neuropsychology, 29(6), 855.

Bentin, S., Deouell, L. Y., \& Soroker, N. (1999). Selective visual streaming in face recognition: Evidence from developmental prosopagnosia. Neuroreport, 10(4), 823-827.

Biotti, F., Gray, K. L., \& Cook, R. (2019). Is developmental prosopagnosia best characterised as an apperceptive or mnemonic condition?. Neuropsychologia, 124, 285-298.

Bobak, A. K., Parris, B. A., Gregory, N. J., Bennetts, R. J., \& Bate, S. (2017). Eye-movement strategies in developmental prosopagnosia and "super" face recognition. The Quarterly Journal of Experimental Psychology, 70(2), 201-217.

Bukach, C. M., Gauthier, I., \& Tarr, M. J. (2006). Beyond faces and modularity: the power of an expertise framework. Trends in cognitive sciences, 10(4), 159-166.

Burns, E. J., Arnold, T., \& Bukach, C. M. (2019). P-curving the fusiform face area: Meta-analyses support the expertise hypothesis. Neuroscience \& Biobehavioral Reviews.

Burns, E. J., Tree, J. J., \& Weidemann, C. T. (2014). Recognition memory in developmental prosopagnosia: electrophysiological evidence for abnormal routes to face recognition. Frontiers in human neuroscience, 8, 622 .

Burns, E. J., Tree, J., Chan, A. H., \& Xu, H. (2019). Bilingualism shapes the other race effect. Vision research, 157, 192-201.

Burns, E., Murray, E., Bennetts, R., Bate, S., Chan, A., \& Xu, H. (2018). Neural origins of cuteness perception and caregiving motivation: evidence from developmental and acquired prosopagnosia. Journal of Vision, 18(10), 920-920.

Burns, E. J., Bennetts, R. J., Bate, S., Wright, V. C., Weidemann, C. T., \& Tree, J. J. (2017). Intact word processing in developmental prosopagnosia. Scientific reports, 7(1), 1683.

Burns, E. J., Martin, J., Chan, A. H., \& Xu, H. (2017). Impaired processing of facial happiness, with or without awareness, in developmental prosopagnosia. Neuropsychologia, 102, 217-228. 
RUNNING HEADER: PROSOPAGNOSIA FIRST FIXATIONS

529 Caldara, R., Schyns, P., Mayer, E., Smith, M. L., Gosselin, F., \& Rossion, B. (2005). Does 530 prosopagnosia take the eyes out of face representations? Evidence for a defect in representing 531 diagnostic facial information following brain damage. Journal of cognitive neuroscience, 17(10), $532 \quad 1652-1666$.

533 Chuk, T., Chan, A. B., \& Hsiao, J. H. (2017). Is having similar eye movement patterns during face 534 learning and recognition beneficial for recognition performance? Evidence from hidden Markov 535 modeling. Vision research, 141, 204-216.

536 Crawford, J.R. \& Howell, D.C. (1998). Comparing an individual's test score against norms derived 537 from small samples. The Clinical Neuropsychologist, 12, 482-486.

538 Crawford, J.R., \& Garthwaite, P.H. (2002). Investigation of the single case in neuropsychology: 539 Confidence limits on the abnormality of test scores and test score differences. Neuropsychologia, $540 \quad 40,1196-1208$.

541 De Haan, E. H. (1999). A familial factor in the development of face recognition deficits. Journal 542 of Clinical and Experimental Neuropsychology, 21(3), 312-315.

543 DeGutis, J., Cohan, S., Mercado, R. J., Wilmer, J., \& Nakayama, K. (2012). Holistic processing 544 of the mouth but not the eyes in developmental prosopagnosia. Cognitive Neuropsychology, 29(5545 6), 419-446.

546 DeGutis, J., Cohan, S., \& Nakayama, K. (2014). Holistic face training enhances face processing 547 in developmental prosopagnosia. Brain, 137(6), 1781-1798.

548 de Xivry, J. J. O., Ramon, M., Lefevre, P., \& Rossion, B. (2008). Reduced fixation on the upper 549 area of personally familiar faces following acquired prosopagnosia. Journal of Neuropsychology, $550 \quad 2(1), 245-268$.

551 Duchaine, B. C. (2000). Developmental prosopagnosia with normal configural 552 processing. Neuroreport, 11(1), 79-83.

553 Duchaine, B., \& Nakayama, K. (2005). Dissociations of face and object recognition in 554 developmental prosopagnosia. Journal of cognitive neuroscience, 17(2), 249-261.

555 Duchaine, B., \& Nakayama, K. (2006). The Cambridge Face Memory Test: Results for 556 neurologically intact individuals and an investigation of its validity using inverted face stimuli and 557 prosopagnosic participants. Neuropsychologia, 44(4), 576-585. 
Duchaine, B., Germine, L., \& Nakayama, K. (2007). Family resemblance: Ten family members with prosopagnosia and within-class object agnosia. Cognitive neuropsychology, 24(4), 419-430.

Duchaine, B., Yovel, G., \& Nakayama, K. (2007). No global processing deficit in the Navon task in 14 developmental people with prosopagnosia. Social cognitive and affective neuroscience, 2(2), 104-113.

Estudillo, A. J., Lee, J. K. W., Mennie, N., \& Burns, E. (2020). No evidence of other-race effect for Chinese faces in Malaysian non-Chinese population. Applied Cognitive Psychology, 34(1), $270-276$.

Fisher, K., Towler, J., \& Eimer, M. (2016). Reduced sensitivity to contrast signals from the eye region in developmental prosopagnosia. cortex, 81, 64-78.

Galaburda, A. M., \& Duchaine, B. C. (2003). Developmental disorders of vision. Neurol Clin, 21(3), 687.

Galton, F. (1883). Inquiries into human faculty and its development. Macmillan.

Gilad, S., Meng, M., \& Sinha, P. (2009). Role of ordinal contrast relationships in face encoding. Proceedings of the National Academy of Sciences, 106(13), 5353-5358.

Gomez, J., Natu, V., Jeska, B., Barnett, M., \& Grill-Spector, K. (2018). Development differentially sculpts receptive fields across early and high-level human visual cortex. Nature communications, 9(1), 1-12.

Grueter, M., Grueter, T., Bell, V., Horst, J., Laskowski, W., Sperling, K., ... \& Kennerknecht, I. (2007). Hereditary prosopagnosia: The first case series. Cortex, 43(6), 734-749.

Haig, N. D. (1985). How faces differ-A new comparative technique. Perception, 14(5), 601-615. Hills, P. J., Cooper, R. E., \& Pake, J. M. (2013). First fixations in face processing: The more diagnostic they are the smaller the face-inversion effect. Acta Psychologica, 142(2), 211-219.

Hsiao, J. H. W., \& Cottrell, G. (2008). Two fixations suffice in face recognition. Psychological Science, 19(10), 998-1006.

Jackson, M. C., Counter, P., \& Tree, J. J. (2017). Face working memory deficits in developmental prosopagnosia: Tests of encoding limits and updating processes. Neuropsychologia, 106, 60-70. Jansari, A., Miller, S., Pearce, L., Cobb, S., Sagiv, N., William, A., Tree, J. J. \& Hanley, R. (2015). The man who mistook his neuropsychologist for a popstar: When configural processing fails in 
RUNNING HEADER: PROSOPAGNOSIA FIRST FIXATIONS

587

588

589

590

591

592

593

594

595

596

597

598

599

600

601

602

603

604

605

606

607

608

609

610

611

612

613

614

615

acquired prosopagnosia. Frontiers in Human Neurroscience., 9: $390-$ doi: 10.3389/fnhum.2015.00390

Jones, R. D., \& Tranel, D. (2001). Severe developmental prosopagnosia in a child with superior intellect. Journal of Clinical and Experimental Neuropsychology, 23(3), 265-273.

Kress, T., \& Daum, I. (2003). Developmental prosopagnosia: A review. Behavioural neurology, 14(3-4), 109-121.

Lee, Y., Duchaine, B., Wilson, H. R., \& Nakayama, K. (2010). Three cases of developmental prosopagnosia from one family: Detailed neuropsychological and psychophysical investigation of face processing. cortex, 46(8), 949-964.

Lee, D. H., Corrow, S. L., Pancaroglu, R., \& Barton, J. J. (2019). The scanpaths of subjects with developmental prosopagnosia during a face memory task. Brain sciences, 9(8), 188.

Luo, C., Burns, E., \& Xu, H. (2017). Association between autistic traits and emotion adaptation to partially occluded faces. Vision research, 133, 21-36.

Lundqvist, D., Flykt, A., \& Öhman, A. (1998). The Karolinska directed emotional faces (KDEF). CD ROM from Department of Clinical Neuroscience, Psychology section, Karolinska Institutet, 91, 630 .

McKenna, P.A.T., \& Warrington, E. K. (1980). Testing for nominal dysphasia. Journal of Neurology, Neurosurgery \& Psychiatry, 43(9), 781-788.

Mehoudar, E., Arizpe, J., Baker, C. I., \& Yovel, G. (2014). Faces in the eye of the beholder: Unique and stable eye scanning patterns of individual observers. Journal of vision, 14(7), 6-6.

Nemeth, K., Zimmer, M., Schweinberger, S. R., Vakli, P., \& Kovács, G. (2014). The background of reduced face specificity of N170 in congenital prosopagnosia. PloS one, 9(7).

Parkington, K. B., \& Itier, R. J. (2018). One versus two eyes makes a difference! Early face perception is modulated by featural fixation and feature context. Cortex, 109, 35-49.

Peterson, M. F., \& Eckstein, M. P. (2012). Looking just below the eyes is optimal across face recognition tasks. Proceedings of the National Academy of Sciences, 109(48), E3314-E3323.

Peterson, M. F., \& Eckstein, M. P. (2013). Individual differences in eye movements during face identification reflect observer-specific optimal points of fixation. Psychological science, 24(7), 1216-1225. 
616 Peterson, M. F., Zaun, I., Hoke, H., Jiahui, G., Duchaine, B., \& Kanwisher, N. (2019). Eye

617 movements and retinotopic tuning in developmental prosopagnosia. Journal of vision, 19(9), 7-7.

618 Riddoch, M. J., \& Humphreys, G. W. (1993). Birmingham object recognition battery. Lawrence

619 Erlbaum Associates.

620 Roth, H. L., Lora, A. N., \& Heilman, K. M. (2002). Effects of monocular viewing and eye dominance on spatial attention. Brain, 125(9), 2023-2035.

Royer, J., Blais, C., Charbonneau, I., Déry, K., Tardif, J., Duchaine, B., ... \& Fiset, D. (2018). Greater reliance on the eye region predicts better face recognition ability. Cognition, 181, 12-20.

Schwarzer, G., Huber, S., Grüter, M., Grüter, T., Groß, C., Hipfel, M., \& Kennerknecht, I. (2007). Gaze behaviour in hereditary prosopagnosia. Psychological research, 71(5), 583-590.

Schyns, P. G., Bonnar, L., \& Gosselin, F. (2002). Show me the features! Understanding recognition from the use of visual information. Psychological science, 13(5), 402-409.

Sormaz, M., Andrews, T. J., \& Young, A. W. (2013). Contrast negation and the importance of the eye region for holistic representations of facial identity. Journal of Experimental Psychology: Human Perception and Performance, 39(6), 1667.

Susilo, T., \& Duchaine, B. (2013). Advances in developmental prosopagnosia research. Current opinion in neurobiology, 23(3), 423-429.

Tardif, J., Morin Duchesne, X., Cohan, S., Royer, J., Blais, C., Fiset, D., ... \& Gosselin, F. (2019). Use of face information varies systematically from developmental prosopagnosics to superrecognizers. Psychological Science, 30(2), 300-308.

636 Towler, J. \& Tree, J. J. (2018). The implications of highly associated face and object impairments 637 of the cognitive architecture. Cognitive Neuropsychology, in press.

638 Van Belle, G., Busigny, T., Lefèvre, P., Joubert, S., Felician, O., Gentile, F., \& Rossion, B. (2011). 639 Impairment of holistic face perception following right occipito-temporal damage in 640 prosopagnosia: converging evidence from gaze-contingency. Neuropsychologia, 49(11), 31456413150.

642 Van Belle, G., De Graef, P., Verfaillie, K., Busigny, T., \& Rossion, B. (2010). Whole not hole: 643 Expert face recognition requires holistic perception. Neuropsychologia, 48(9), 2620-2629. 
644 Verfaillie, K., Huysegems, S., De Graef, P., \& Van Belle, G. (2014). Impaired holistic and analytic 645 face processing in congenital prosopagnosia: Evidence from the eye-contingent mask/window 646 paradigm. Visual Cognition, 22(3-4), 503-521.

647 Vinette, C., Gosselin, F., \& Schyns, P. G. (2004). Spatio-temporal dynamics of face recognition 648 in a flash: It's in the eyes. Cognitive Science, 28(2), 289-301.

649 Warrington, E. K. (1984). Recognition Memory Test: Rmt.(Words). Test Booklet 1. NFER650 Nelson Publishing Company.

651 Warrington, E. K. (1997). The graded naming test: a restandardisation. Neuropsychological 652 Rehabilitation, 7(2), 143-146. 